\title{
Mutual Coupling and Its Effect on Steady-State Performance and Position Estimation of Even and Odd Number Phase Switched Reluctance Motor Drive
}

\author{
Debiprasad Panda ${ }^{1,2}$ and V. Ramanarayanan ${ }^{3}$ \\ ${ }^{1}$ Indian Institute of Science, Bangalore 560012, India \\ ${ }^{2}$ Trans-Coil Inc., Milwaukee, WI 53224 USA \\ ${ }^{3}$ Department of Electrical Engineering, Indian Institute of Science, Bangalore 560012, India
}

\begin{abstract}
In this paper, we analyze mutual coupling of switched reluctance (SR) motors with even and odd numbers of phases. We illustrate that SR motors with an even number of phases produce asymmetric mutual flux in different phases. On the other hand, an SR motor with an odd number of phases produces symmetric mutual coupling in all the phases. Then, we explain a practical way of measuring the mutual flux in SR motors and present the test results for an 8/6 pole, four-phase $4 \mathrm{~kW}$ motor. We simulated the performance of the SR motor with and without mutual flux, thereby demonstrating the effect of mutual flux on phase current, flux, and average torque. We verified the effect of mutual flux on position estimation by simulation and experiment. We show that appropriate correction for mutual flux may improve the accuracy of estimated position by $3^{\circ}$, which will give better performance of the drive while driven without any shaft sensors. We also show that an SR motor with an odd number of phases is a better choice than one with an even number of phases because of its symmetric mutual coupling, its ability to utilize short flux paths, and the fact that it does not require costly bipolar excitation.
\end{abstract}

Index Terms-Mutual flux, mutual flux measurement, position estimation, SR motor, steady-state performance, symmetric and asymmetric mutual coupling.

\section{INTRODUCTION}

$\mathbf{T}$ HE design, performance evaluation, and high-performance control of switched reluctance (SR) motors requires detailed knowledge of the flux-linkage characteristics of the windings for different rotor positions at different excitation currents. Most of the existing literature [1], [2], [5], [6], [13] employs flux-linkage characteristics obtained from static tests or through finite-element method. Dynamic effects and mutual couplings between different phases are ignored. With limited analysis, Moghbelli et al. [3] has shown earlier through finite-element analysis that mutual coupling can cause errors in the flux-linkage characteristics as much as $7 \%$ [3]. The effect of mutual coupling in the unexcited phase is reported in [8] and [9]. However, their analysis and experiment was restricted only on the idle phase in the form of induced voltage during normal and abnormal operating conditions. The effect of mutual flux on the steady-state performance or its effects on position estimation were not reported in those papers. Preston et al. [16] proposed an equivalent circuit model considering mutual coupling effect in SR motor and they compare their model with finite-element results. However, actual test results on mutual flux were not reported in that paper. Test results of mutual flux only in very limited operating conditions for an $8 / 6$ pole SR motor were reported in [17]. Also, it failed to identify the asymmetric nature of the mutual coupling on different phases. To the best knowledge of the authors, the detailed experimental results of mutual flux and their effect on motor performance and sensorless operation had not been reported until the present authors published their results in conferences in 1998 [14] and 1999 [4], respectively, as a subset of this present paper. Later on, many other authors [15], [18]-[20] also discussed the effect

Digital Object Identifier 10.1109/TMAG.2007.898101 of mutual inductance. However, in most of these publications, the effects of mutual inductance were discussed only for a particular motor and winding configuration and also supported by very limited or no test results. The effects of mutual coupling on different configurations such as for even and odd number phase motors and also their effect on position estimation had not been reported.

Traditionally, a SR motor needs position sensors for satisfactory control. Generally, absolute encoder or discrete optical and magnetic sensors are used for position sensing. These sensors inherently reduce the reliability of the drive. Extensive application of SR motor will require development of robust sensorless control. Such sensorless control schemes need accurate position estimation, which in turn needs accurate evaluation of flux-linkage characteristics accounting for the non-idealities of dynamic effects and mutual coupling.

In this paper, first the importance of mutual coupling in SR motors is discussed. Then, a qualitative study on even and odd number of phase SR motors, possible winding configurations, and mutual coupling path is studied. After that, a practical method for mutual flux measurement in SR motors is illustrated. Measurement method, experimental setup, and test results are presented. The asymmetry due to mutual coupling on the phase currents, phase fluxes, and energy conversion contours of an even number of phase motors are demonstrated through the test and dynamic simulation. A detailed discussion on the effect of mutual coupling on the performance and the choice of an even and odd number phase SR motor has been presented. The effect of saturation on mutual coupling effect has also been discussed. This paper then attempts to model the mutual coupling effects on the flux-linkage characteristics and a more accurate position estimation algorithm considering the mutual coupling is presented. The schematic of the position estimator, controller, power converter, and a complete photograph of the hardware setup is given, and finally conclusions are made. 


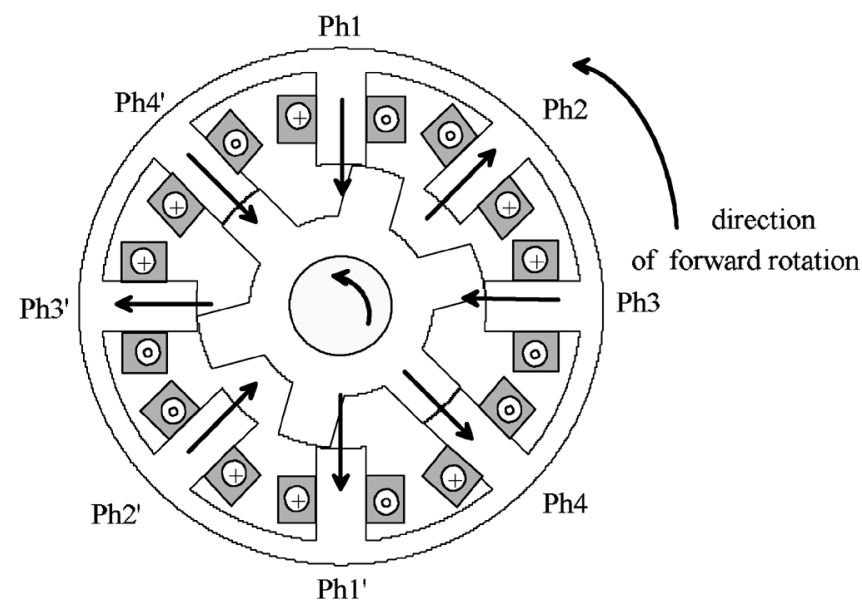

(a)

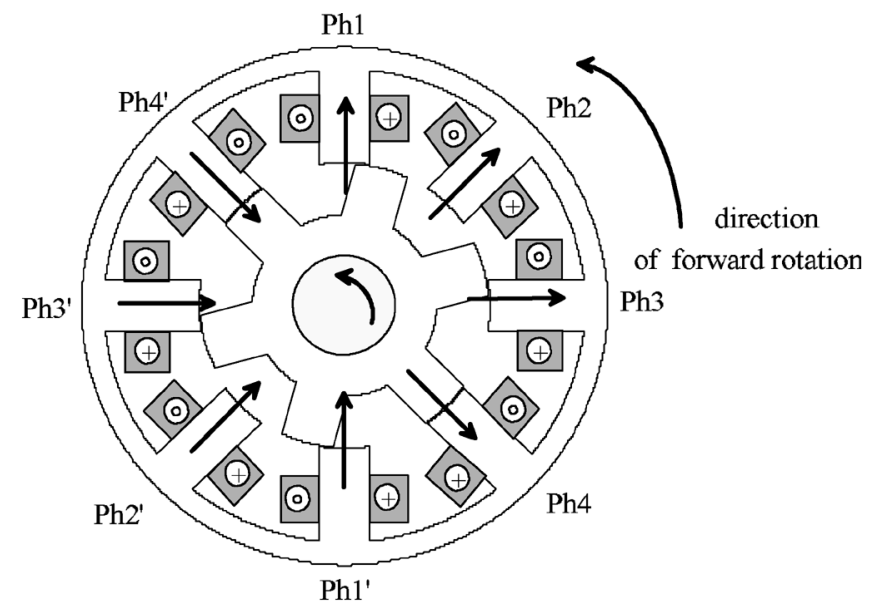

(b)

Fig. 1. (a) Designed flux pattern and (b) alternate flux pattern at poles of a four-phase 8/6 SR motor.

\section{Mutual FluX AND Its MeAsurement}

The measurement of static flux-linkage characteristics are well documented in literature [5], [6]. In those measurements, excitation is given to only one phase while other phases are kept open. These off-line measured characteristics do not take into account the mutual fluxes due to the other phases. During dynamic operation, more than one phase will have excitation currents at a time and the flux-linkages of each phase will be influenced by the currents in the other conducting phases. Hence, proper modeling and accurate analysis require the knowledge of mutual fluxes in addition to the flux linkage characteristics of the individual phases.

\section{A. Mutual Coupling in SR Machines With Even and Odd Number of Phases}

In the test motor, the winding connections are such that the direction of the fluxes (marked by arrows) in each of the individual phases are as shown in Fig. 1(a). The arrows in Fig. 1(a) indicate the direction of the individual phase fluxes. The figure suggests that the mutual flux will not be in the same direction for all the phases. For example, the mutual flux in $\mathrm{Ph} 2$ and $\mathrm{Ph} 3$ due to their neighboring phases are additive for the given winding connection. On the contrary, the mutual coupling in $\mathrm{Ph} 1$ and $\mathrm{Ph} 4$ are in opposing nature. Hence, when $\mathrm{Ph} 2$ and $\mathrm{Ph} 3$ are simultaneously excited the mutual flux becomes additive. The same is true when $\mathrm{Ph} 1-\mathrm{Ph} 2$ and $\mathrm{Ph} 3-\mathrm{Ph} 4$ are excited together. Thus, for $\mathrm{Ph} 1-\mathrm{Ph} 2$, $\mathrm{Ph} 2-\mathrm{Ph} 3$, and $\mathrm{Ph} 3-\mathrm{Ph} 4$ combinations, the mutual flux adds on to the self flux of individual winding and the net flux of the windings increase which in turn will increase the average torque of the above excitation combinations. However, for $\mathrm{Ph} 4-\mathrm{Ph} 1$ excitation, the mutual flux will oppose the self flux of the individual windings and the total flux will be reduced which in turn will reduce the produced torque. Hence, the fluxes in the windings and torque produced by individual phases will differ due to such asymmetric mutual coupling from phase to phase.

The alternative winding design can be made as given in Fig. 1(b) and the direction of fluxes for such design are marked by arrows. It may be seen that the direction of fluxes in the adjacent windings for $\mathrm{Ph} 1, \mathrm{Ph} 2, \mathrm{Ph} 3$, and $\mathrm{Ph} 4$ are the same. For such windings, the mutual flux will oppose the self flux in $\mathrm{Ph} 1-\mathrm{Ph} 2, \mathrm{Ph} 2-\mathrm{Ph} 3$, and $\mathrm{Ph} 3-\mathrm{Ph} 4$ excitation combinations. On the other hand, it will be additive in case of $\mathrm{Ph} 4-\mathrm{Ph} 1$ case. Thus, the mutual flux in all the phases will not be symmetric. Also, this type of winding arrangement will reduce the net average torque of the machine since most of the phase fluxes will be reduced due to mutual coupling. Thus, the winding arrangement given in Fig. 1(a) will be superior in terms of net torque production compared to the machine in Fig. 1(b). However, it can be concluded that in both the above cases, the mutual fluxes of the windings are asymmetric in nature. Such asymmetry in mutual coupling can be illustrated in any SR motor comprising with even number of phases.

On the other hand, if the machine is designed with an odd number of phases (say three or five phases, etc.), the mutual fluxes can be made additive and symmetric for all the phases following the winding design method similar to Fig. 2(a). It can be seen from Fig. 2(a) that mutual flux is always additive to the self flux for all excitation combinations ( $\mathrm{Ph} 1-\mathrm{Ph} 2, \mathrm{Ph} 2-\mathrm{Ph} 3$, and $\mathrm{Ph} 3-\mathrm{Ph} 1)$. Hence, it can be concluded that a SR motor with odd number of phases and with windings of alternate polarities as given in Fig. 2(a) will utilize the mutual flux the best and also maintain symmetry between the phases. This winding configuration in Fig. 2(a) also inherently supports the short flux path with unipolar excitation for all the phases. Therefore, costly bipolar excitation [12] is redundant in case of an odd number of phase motors. However, an odd number of phase SR motor can also be designed alternatively as given in Fig. 2(b), which again creates asymmetric mutual flux between the phases. In the later configuration, the mutual flux will oppose the self flux in $\mathrm{Ph} 1-\mathrm{Ph} 2$ and $\mathrm{Ph} 2-\mathrm{Ph} 3$ combination and adds to self flux during $\mathrm{Ph} 3-\mathrm{Ph} 1$ combination. Such winding configuration obviously will reduce the net torque in the motor and will not support short flux path. Therefore, the winding configuration in Fig. 2(a) will be a clear choice for an odd number of phase SR motor.

In this paper, an example of a four-phase SR motor will be discussed as a representative of even number of phase motor for demonstrating asymmetric mutual flux. The effect of mutual 


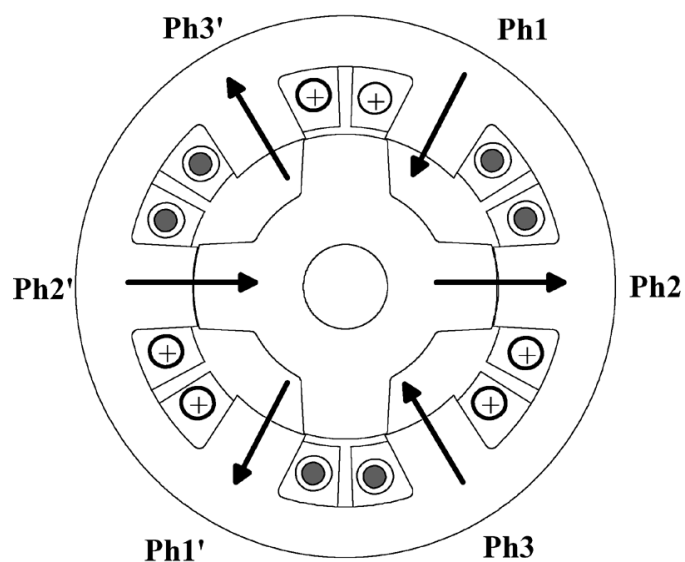

(a)

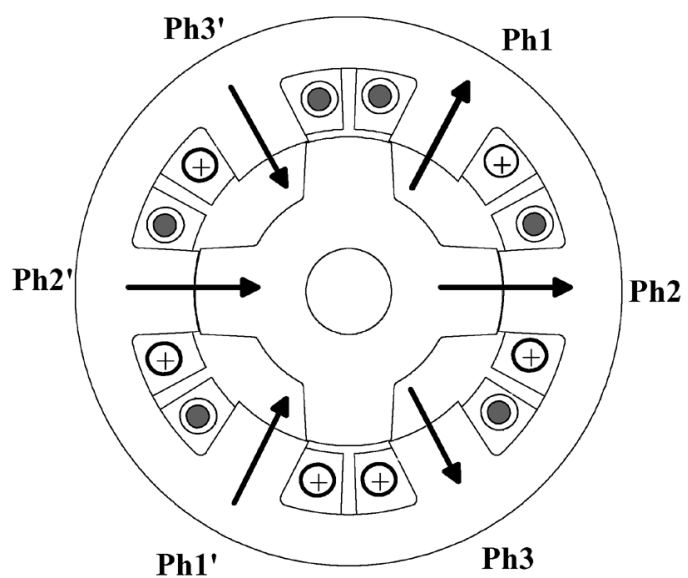

(b)

Fig. 2. (a) Symmetric mutual flux pattern and (b) asymmetric mutual flux pattern at poles of a three-phase 6/4 SR motor.

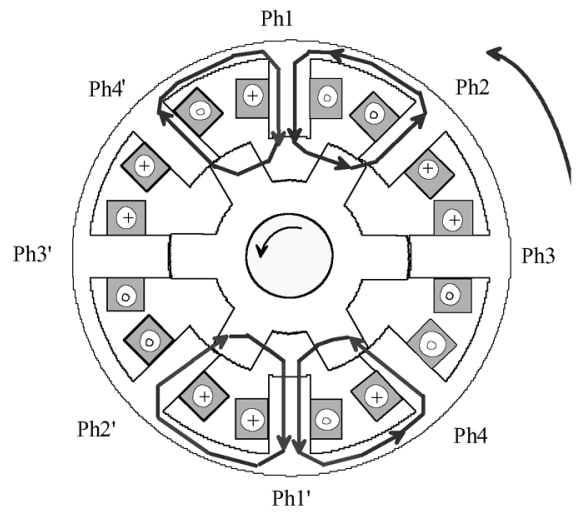

(a)

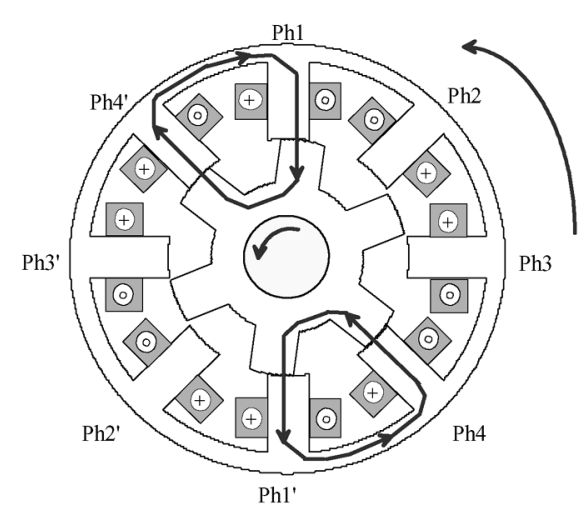

(b)

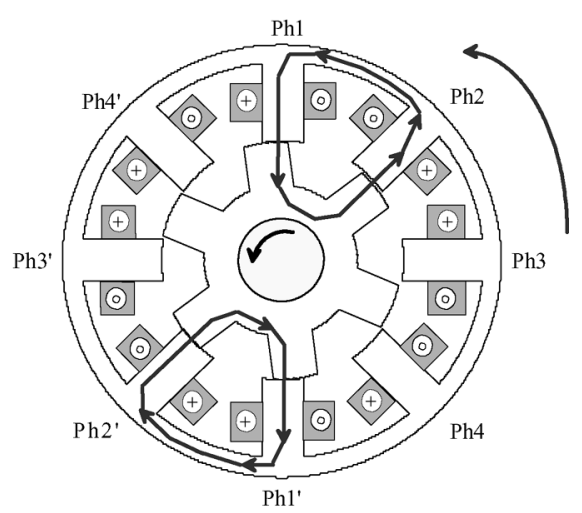

(c)

Fig. 3. Mutual flux-linkages of a four-phase $8 / 6$ pole SR motor to its neighboring phases when $\mathrm{Ph} 1$ is excited: (a) $\mathrm{Ph} 1$ is at $0^{\circ}$, (b) $\mathrm{Ph} 1$ at $22.5^{\circ}$, (c) $\mathrm{Ph} 1$ is at $37.5^{\circ}$.

flux on its performance and sensorless operation will also be illustrated. The typical mutual flux pattern due to $\mathrm{Ph} 1$ of a fourphase SR motor with its neighboring phases $(\mathrm{Ph} 4$ and $\mathrm{Ph} 2)$ are shown in Fig. 3(a)-(c). When Ph1 is at $0^{\circ}$ [Fig. 3(a)], the mutual linkage due to $\mathrm{Ph} 1$ with both its neighboring phases are equal. At $22.5^{\circ}$ [Fig. 3(b)], the mutual coupling between $\mathrm{Ph} 1$ and $\mathrm{Ph} 4$ will be maximum as the air gap between the stator and the rotor along the mutual flux path is minimum at that position. Similarly, at $37.5^{\circ}$ [Fig. 3(c)], the mutual coupling between $\mathrm{Ph} 1$ and $\mathrm{Ph} 2$ is maximum. The mutual coupling at other angular positions will take intermediate values. An experiment is conducted to verify the nature and measure the magnitude of mutual fluxes of each phase. The details of the experiment are explained next.

\section{B. Measurement of Mutual Flux}

The experimental setup for measuring mutual flux in a SR motor is given in Fig. 4. During the experiment, the rotor is held standstill at a predetermined position using an indexing head and a disk with position marking is mounted on the shaft of the motor for verifying the position of the rotor. One of the phases of the motor is connected in series with a rheostat (Rh) and an electronic switch (S) to a dc source, with all other phases open. Voltages are induced in the unenergized phases due to the rate of change of current in the active phase. The induced voltages in

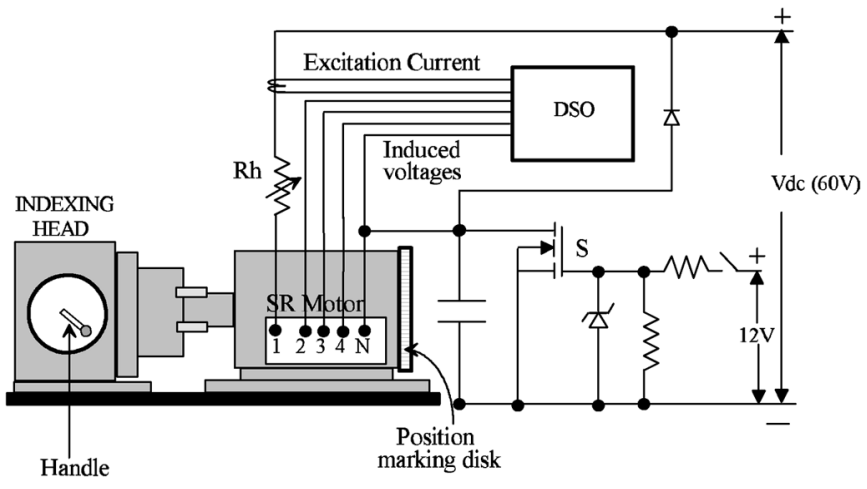

Fig. 4. Experimental setup for mutual flux-linkage measurement (1,2,3,4 represents the different phase and $\mathrm{N}$ is the neutral connection of the phase windings).

the unenergized phases and the current through the active phase are recorded and stored in a digital storage oscilloscope (DSO). The rheostat $(\mathrm{Rh})$ is used to limit the current to the required value. The experiment is conducted over a complete electric cycle $\left(60^{\circ}\right.$ mechanical) and the test results are stored for every $2^{\circ}$. The typical test results of current in the active phase and induced voltages in the other phases due to the main phase current are shown in Fig. 5(a) and (d). From the plots, it can be seen that the induced voltage in the phase in quadrature $(\mathrm{Ph} 3)$ with the excited phase (Ph1) is very much less compared to the 
(a)
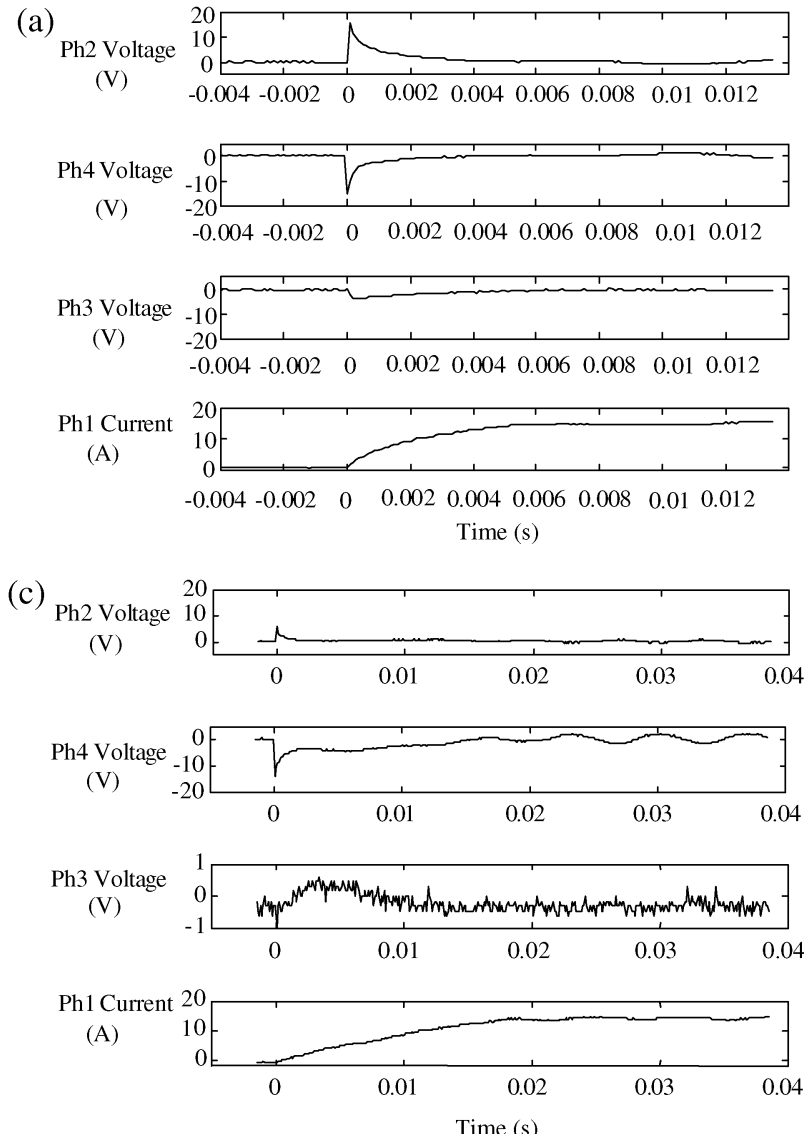

(b)
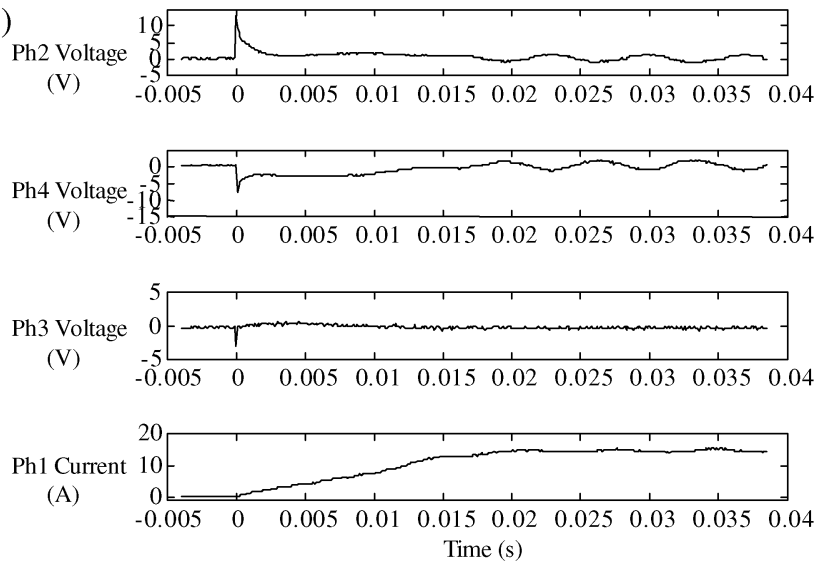

(d)
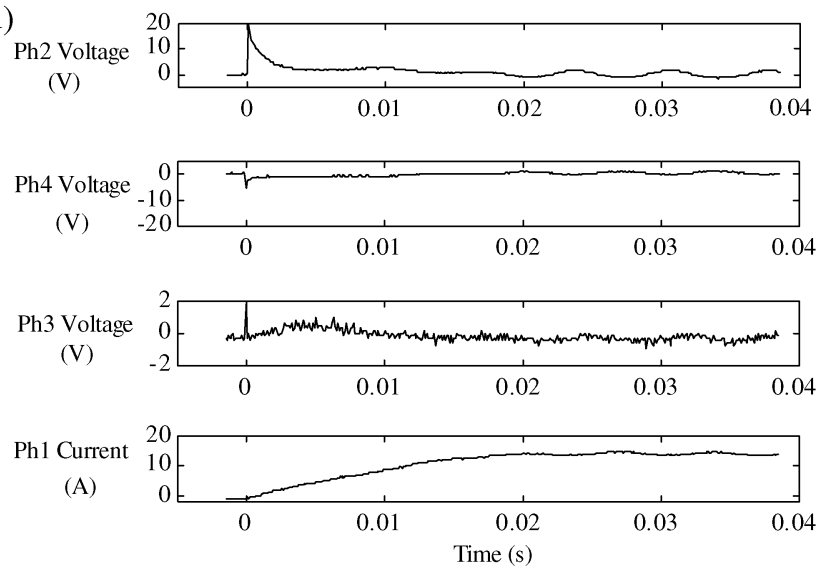

Fig. 5. Mutually induced voltages in different phases due to excitation in phase 1 at (a) position $0^{\circ}$, (b) position $30^{\circ}$, (c) position $22.5^{\circ}$, and (d) position $37.5^{\circ}$.

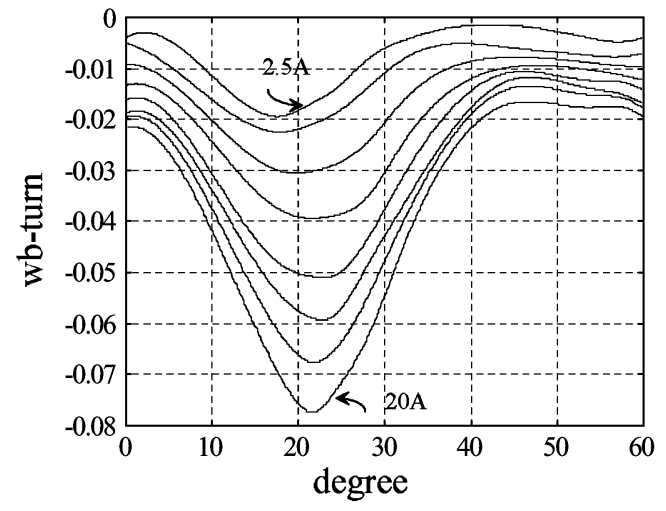

(a)

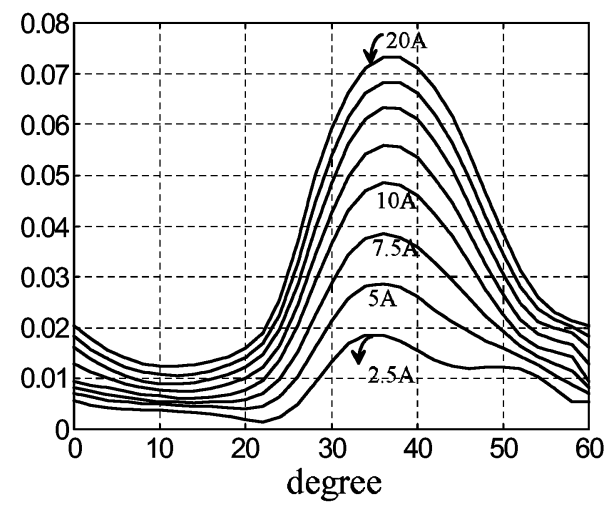

(b)

Fig. 6. Experimentally obtained mutual flux-linkages in (i) $\mathrm{Ph} 4$ and (ii) $\mathrm{Ph} 2$ for the different excitation currents (0:2.5:20 A) in $\mathrm{Ph} 1$.

adjacent phases ( $\mathrm{Ph} 2$ and $\mathrm{Ph} 4$ for this case). Hence, the mutual linkage due to the quadrature phase may be ignored. It can also be observed that the induced voltage waveforms in the two neighboring phases of the active phase are similar both at $0^{\circ}$ and $30^{\circ}$ [see Fig. 5(a) and (b)]. The magnetic path in Fig. 3(a) justifies this phenomenon. The mutual linkage with $\mathrm{Ph} 4$ and $\mathrm{Ph} 2$ are maximum when $\mathrm{Ph} 1$ is at $22.5^{\circ}$ and $37.5^{\circ}$, respectively. These observations also can be justified by Fig. 3(b) and Fig. 3(c). The mutual flux $\Psi_{j k}$ is computed through the numerical integration of the induced voltage $v_{j k}$ in the $j$ th phase due to the excitation in the $k$ th phase and that is given by the following equation:

$$
\Psi_{j k}=\int\left(v_{j k}\right) d t .
$$

The typical plots of the computed mutual flux-linkages are shown over a complete electrical cycle in Figs. 6 and 7 for different excitation currents. In these plots, $x$-axis represents the relative position of the rotor pole with respect to the phase being excited and these positions are meant for forward rotation of the motor (the arrows in Fig. 1(a) and Fig. 3 indicate the forward rotation). The same experiment is repeated for different phases and each time the mutual flux to the neighboring phases are computed.

\section{Discussion}

The test results confirm that the mutual flux in the neighboring phases are identical in magnitude for all the phases. Some 


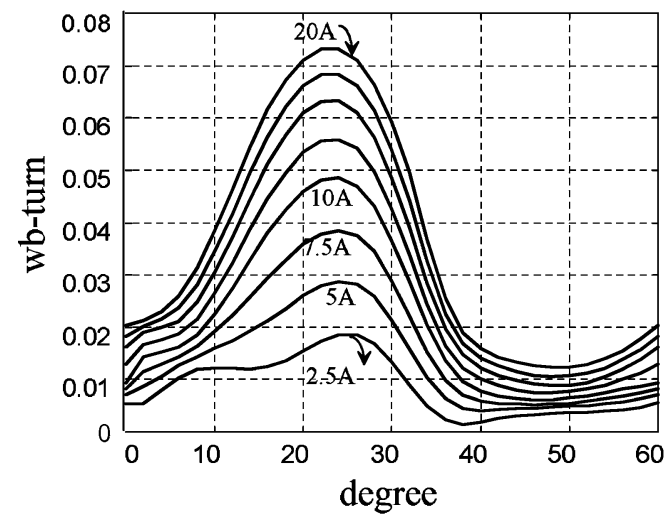

(a)

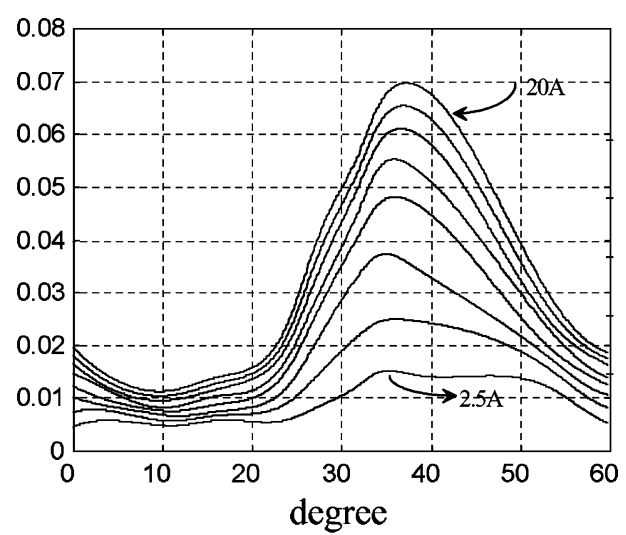

(b)

Fig. 7. Experimentally obtained mutual flux-linkage in (i) $\mathrm{Ph} 2$ and (ii) $\mathrm{Ph} 4$ for the different excitation currents $(0: 2.5: 20 \mathrm{~A})$ in $\mathrm{Ph} 3$.

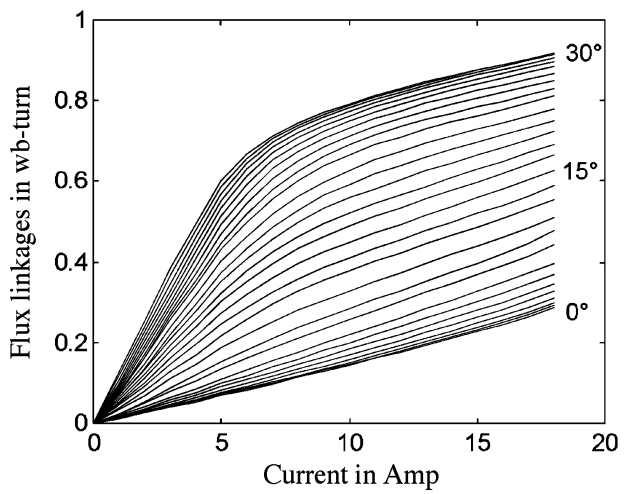

Fig. 8. Experimental static flux-linkage characteristics of a $4 \mathrm{~kW} \mathrm{8/6} \mathrm{pole} \mathrm{SR}$ motor.

minor difference in magnitude is observed which could be due to manufacturing non-idealities between the phases or could be due to instrumentation error or due to both. However, the difference is so small it can be neglected. On the contrary, the direction of the mutual fluxes in different phases are clearly not the same. The direction depends on the winding connection, which is a designer prerogative. It may be seen in Figs. 6 and 7 that the mutual flux at $22.5^{\circ}$ with the preceding phase (phase sequence is $\mathrm{Ph} 1-\mathrm{Ph} 2-\mathrm{Ph} 3-\mathrm{Ph} 4-\mathrm{Ph} 1)$ is maximum. Similarly, at $37.5^{\circ}$ the mutual flux with the following phase is at maximum. This is in conformity with the earlier comments with respect to Fig. 3(a)-(c). It is observed that the magnitude of peak mutual flux linkage is maximum at $22.5^{\circ}$. The adjacent phase with rated current $(18 \mathrm{~A})$ can induce as much as $0.075 \mathrm{wb}$-turn mutual flux at this position. If we assume that the given phase also carries rated current simultaneously, then it induces a self flux of 0.86 wb-turn on its own. Thus, mutual flux becomes almost $8.75 \%$ of the self flux at this position. However, the self flux linkage is maximum at the aligned position ( $30^{\circ}$ for this case). At rated current the maximum flux-linkage is observed at this position and which is 0.915 wb-turn for this test motor. However, the maximum mutual flux-linkage at this position due to the neighboring phases could be 0.055 wb-turn which is around $6 \%$ of the self-flux linkage. So, we can conclude that the maximum mutual coupling for the test motor occurs at $22.5^{\circ}$ position and its magnitude can be as high as $8.75 \%$. The static flux-linkage characteristics of the test motor are given in Fig. 8. Analysis and

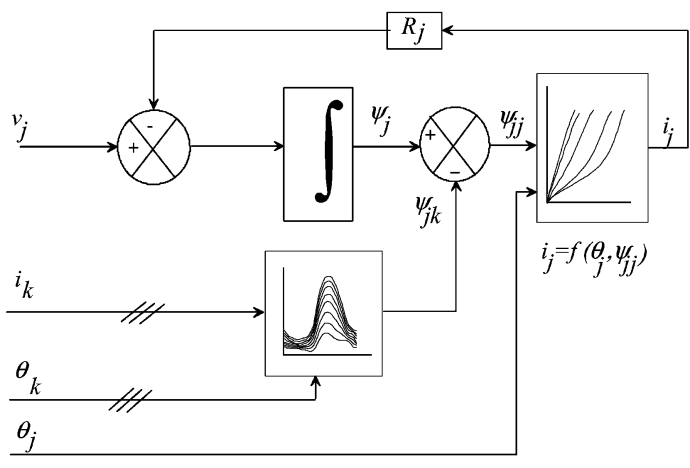

Fig. 9. Simulation block diagram (considering mutual flux).

quantification of mutual flux-linkage is useful for various reasons. Its influence in dynamic condition can be studied through simulation. In many position estimation algorithms of SR motor, the flux-linkage characteristics may be corrected for these mutual fluxes to obtain higher accuracy in estimation.

\section{Modeling And Performance Evaluation of SR Motor With Mutual FLuX}

The electromagnetic characteristics of the SR motor may be represented by the following equations:

$$
\begin{aligned}
v_{j} & =i_{j} R_{j}+\frac{d \Psi_{j}}{d t} \\
\Psi_{j} & =\Psi_{j j}+\sum_{(k=1,2,3,4),(j \neq k)} \Psi_{j k} \\
\Psi_{j k} & =f\left(i_{k}, \theta_{k}\right) \\
W_{j}^{\prime} & =\int \Psi_{j} d i_{j} \\
T_{a v j} & =\frac{\Delta W_{j}^{\prime}}{\Delta \theta_{j}}
\end{aligned}
$$

where $v_{j}, R_{j}, i_{j}, \Psi_{j}, \Psi_{j j}, \Psi_{j k}$, and $\theta_{j}$ represent the voltage, resistance, current, net flux-linkage, self flux-linkage, mutual fluxlinkage, and relative position of the active phase ( $j$ th phase). The current and position of the other conducting phases ( $k$ th phase) are represented as $i_{k}$ and $\theta_{k}$, respectively; the average torque, 
(a)

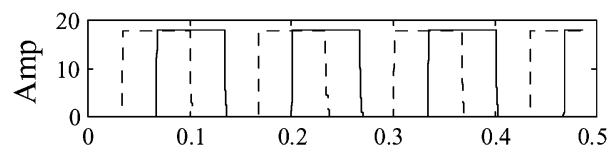

(ii)

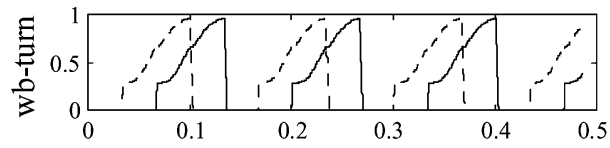

(iii)

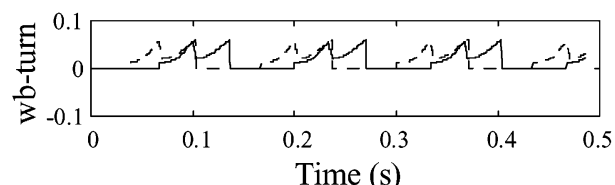

Currents, Net Flux and Mutual Flux at $75 \mathrm{rpm}$ and full load

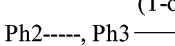

(b)

(i)

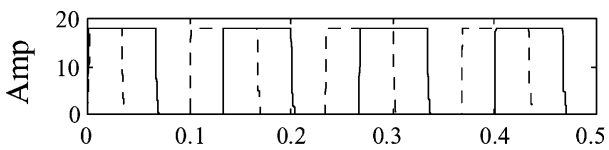

(ii)

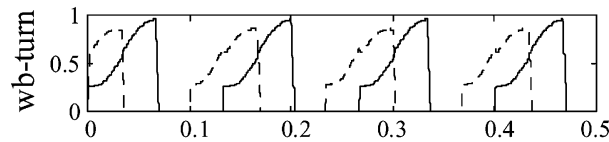

(iii)

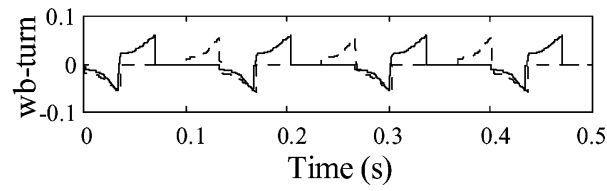

Currents, Net Flux and Mutual Flux at $75 \mathrm{rpm}$ and full load (T-on $=0$ and $\mathrm{T}$-off $=30$ )

Ph4------, Ph1

Fig. 10. Simulation results at 75 rpm and full load: (i) current, (ii) net flux, (iii) mutual flux for (a) $\mathrm{Ph} 2$ and $\mathrm{Ph} 3$; and (b) $\mathrm{Ph} 1$ and $\mathrm{Ph} 4$.
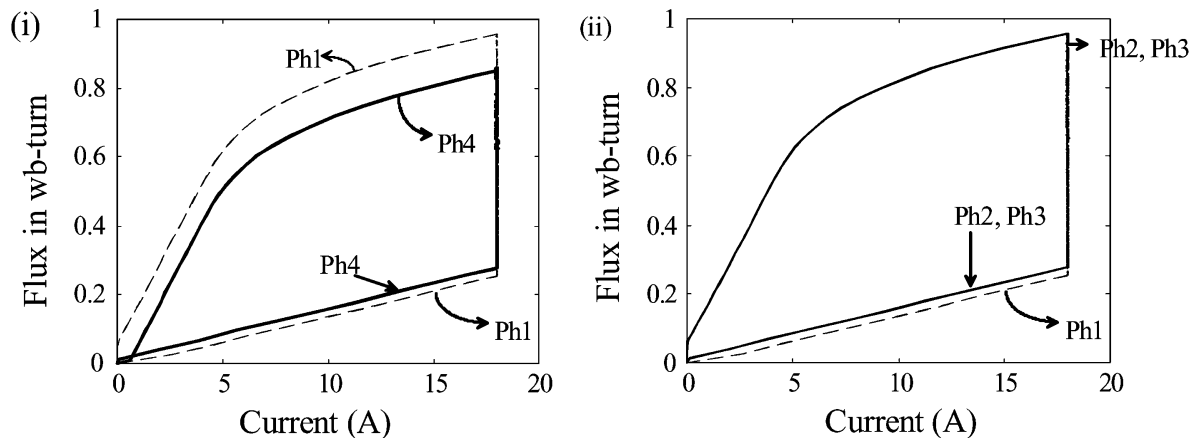

Fig. 11. Comparison of energy conversion loops with mutual fluxes (i) between Ph1 and Ph4 and (ii) between Ph1 and Ph2 (Ph3) at 75 rpm and full load.

co-energy, and conduction angle of the active phase are represented as $\operatorname{Tav}_{j}, W_{j}^{\prime}$, and $\Delta \theta_{j}$, respectively. Average torque due to a particular phase over a complete phase cycle is computed from the change in co-energy during that cycle using (6). Measured mutual flux-linkage and static flux-linkage characteristics as given in Figs. 7-9 are stored in the form of lookup tables. The well-known time step integration method is used for simulation [6]. The following assumptions are made:

1) eddy-current effects are neglected;

2) dc bus voltage is assumed to be ripple free;

3) superposition theorem holds good for mutual flux during saturation.

The phase voltage is a function of the dc supply voltage and the states of the switches in the controller. At any instant, the phase flux linkage is obtained by integrating (2) over the previous time step. Now with a known position $\theta_{j}$ and known flux $\Psi_{j}$, the value of $i_{j}$ may be found using pre-stored static fluxlinkage characteristics $\left(i_{j}=f\left(\theta_{j}, \Psi_{j j}\right)\right)$. In this process mutual flux is ignored. While mutual fluxes are considered, the flux obtained through (2) should be corrected for the mutual flux due to the other conducting phases. This corrected flux is the self flux $\left(\Psi_{j j}\right)$. Knowing self flux and position, the corresponding current may be obtained following the same process as mentioned above. The detailed simulation block diagram is given in Fig. 9. The conventional control method employs two regimes of control namely low-speed chopping control and high-speed pulse width control [6]. In order to illustrate the effect of mutual cou- pling throughout the speed range, two case studies - one at very low speed $(75 \mathrm{rpm})$ and another at rated speed (1500 rpm) - are presented here.

\section{A. Case 1: Low-Speed Operation}

Simulation is carried out at very low speed (75 rpm) with T-on (position at which phases start conducting) and T-off (position at which phases are switched off) angles at $0^{\circ}$ and $30^{\circ}$, respectively; current reference $\mathrm{I}^{*}$ at $18 \mathrm{~A}$ and dc excitation voltage at $280 \mathrm{~V}$. The switching frequency of the converter is assumed to be large (200 kHz in this case). The simulation results of phase current, net flux, and mutual flux waveforms in the different phases are given in Fig. 10. It can be seen that the flux patterns are not the same for all phases. The flux waveforms for $\mathrm{Ph} 2$ and $\mathrm{Ph} 3$ are similar, whereas they are different for $\mathrm{Ph} 4$ and $\mathrm{Ph} 1$. The peak flux of $\mathrm{Ph} 4$ is less compared to all other phases. Hence, the flux-current contours for each of the phases are expected to follow different trajectories. It is well known that the average torque of any phase is proportional to the area covered by its energy conversion loop [6] in one phase cycle. Hence, the average torque produced in all the phases will not be identical. At $75 \mathrm{rpm}$ and full load, the energy conversion loops of all the phases are compared in Fig. 11. The results show that the average torque produced in $\mathrm{Ph} 1$ will be maximum and that in $\mathrm{Ph} 4$ will be minimum. The average torque in $\mathrm{Ph} 2$ and $\mathrm{Ph} 3$ are equal but they are less than that in $\mathrm{Ph} 1$ and more than that in $\mathrm{Ph} 4$. Hence, it can be concluded that for a fixed current opera- 
(i)

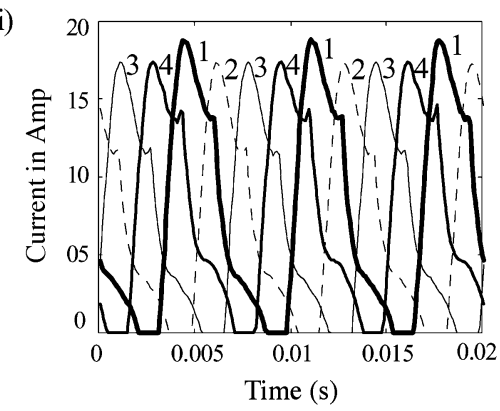

(ii)

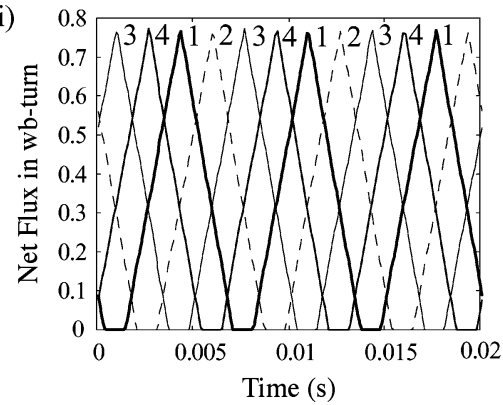

(iii)

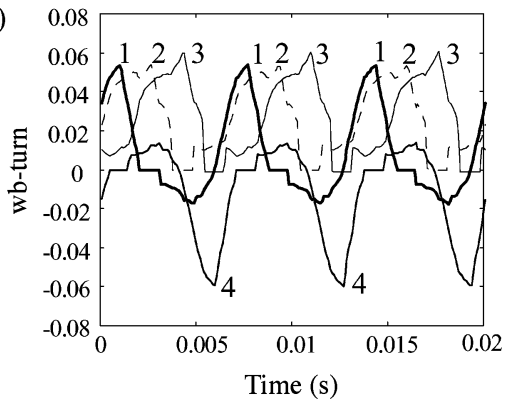

Fig. 12. Simulation results at $1500 \mathrm{rpm}$ and full load: (i) currents, (ii) net fluxes, and (iii) mutual flux-linkages for different phases. 1-2-3-4 represents the Ph1, $\mathrm{Ph} 2, \mathrm{Ph} 3$, and $\mathrm{Ph} 4$, respectively.

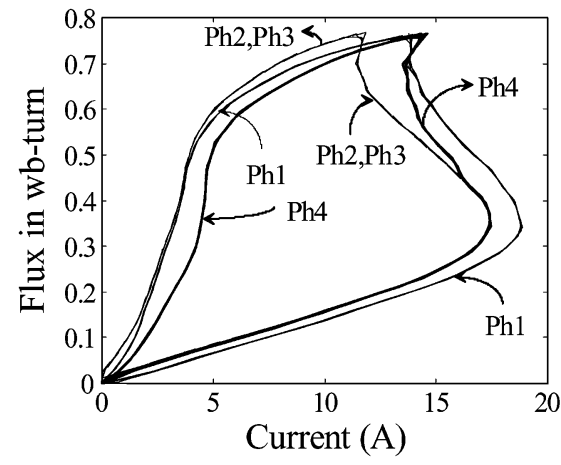

Fig. 13. Comparison of energy conversion loops (considering mutual flux) of different phases at $1500 \mathrm{rpm}$ and full load.

tion and fixed T-on and T-off angles, the load sharing varies in different phases due to mutual inductance effect. This may also introduce extra torque ripple in the SR motor.

\section{B. Case 2: High-Speed Operation}

Similar results at rated speed $(1500 \mathrm{rpm})$ and rated load are shown in Figs. 12 and 13. At this operating point, the current (torque) is controlled by the angle control mode [6], [7]. The $\mathrm{T}$-on and T-off angles are fixed at $-3.75^{\circ}$ and $22.5^{\circ}$, respectively, dc excitation voltage is kept constant at $280 \mathrm{~V}$; speed of the motor is set at $1500 \mathrm{rpm}$ and the simulation is conducted under these conditions. The current, net flux, and mutual fluxlinkage in all the phases are plotted in Fig. 12 (i), (ii), and (iii). The results show that the current waveforms in all the phases are not the same. The peak current in $\mathrm{Ph} 1$ is maximum and that in $\mathrm{Ph} 2, \mathrm{Ph} 3$, and $\mathrm{Ph} 4$ are almost equal. At the commutation points, the current in $\mathrm{Ph} 4$ is maximum followed by $\mathrm{Ph} 1$. At this point, the currents in $\mathrm{Ph} 2$ and $\mathrm{Ph} 3$ are the same but less than that in $\mathrm{Ph} 1$. The energy conversion loops are compared for different phases in Fig. 13. These results show that the shape of the energy conversion loops are same for $\mathrm{Ph} 2$ and $\mathrm{Ph} 3$ but differ considerably for $\mathrm{Ph} 1$ and $\mathrm{Ph} 4$. Hence, the torque produced in different phases will not be the same. Consequently, the windings in different phases will not be utilized equally.

\section{Position Estimation Through FluX-Current Method}

Flux-current method [10], [11] is one of the most popular methods for position estimation of SR motor. Measuring the voltage across and current through the winding, the flux-linkage of any phase may be computed using (2). Knowing the current and flux, the position of the rotor may be estimated using the off-line measured static flux-linkage characteristics. Lyons [10] suggested this method in the early 1990s. In this paper, they also mentioned about possible mutual coupling and suggested an equivalent circuit model of the motor in order to take into account the mutual coupling effect. However, the effect on position estimation accuracy has not been quantified by a proper comparison with or without considering mutual coupling effect. In our paper, the off-line measured mutual flux is used for correcting the flux-linkage of the active phase and this corrected flux is used for position estimation. Finally, the accuracy of estimated position with and without mutual flux is quantified by proper comparison.

\section{A. Position Estimator Realization}

The block diagram of the position estimator following the above method is shown in Fig. 14. Six analog signals (the four phase currents and two dc link voltages) are taken as inputs through ADC. All analog signals are processed through software low-pass filter (LF) to attenuate the switching and high-frequency noises. The estimator logic generation block decides on the active phase. The computed flux obtained through the integration is further corrected for mutual flux due to the other conducting phases. Notice that the integration shown in Fig. 14 is multidimensional. This corrected flux may be treated as same as the static flux-linkage characteristics. From the corrected flux and the active phase current, position is looked up from the stored static flux-linkage characteristics. The lookup tables are obtained through off-line measurements as mentioned earlier. First, a lookup table for static flux-linkage characteristics as a function of current and position. The data are stored for 1:1:20 A and 1:1:30 . Thus, the size of the lookup table is 600 word. Similarly, another lookup table of mutual flux for complete one cycle $\left(60^{\circ}\right.$ for this case) is stored as a function of current and rotor position with a resolution of 1:1:20 A and 2:2:60 (the mutual coupling at $0^{\circ}$ and $60^{\circ}$ will be the same). Therefore, the size of mutual flux lookup table is also 600 word. The magnitude of the mutual flux for all the phases are assumed to be the same. On the other hand, the direction of mutual coupling depending on the relative winding configuration (see Fig. 1(a) and Fig. 3) will be either positive or negative and has been taken care of accordingly. 


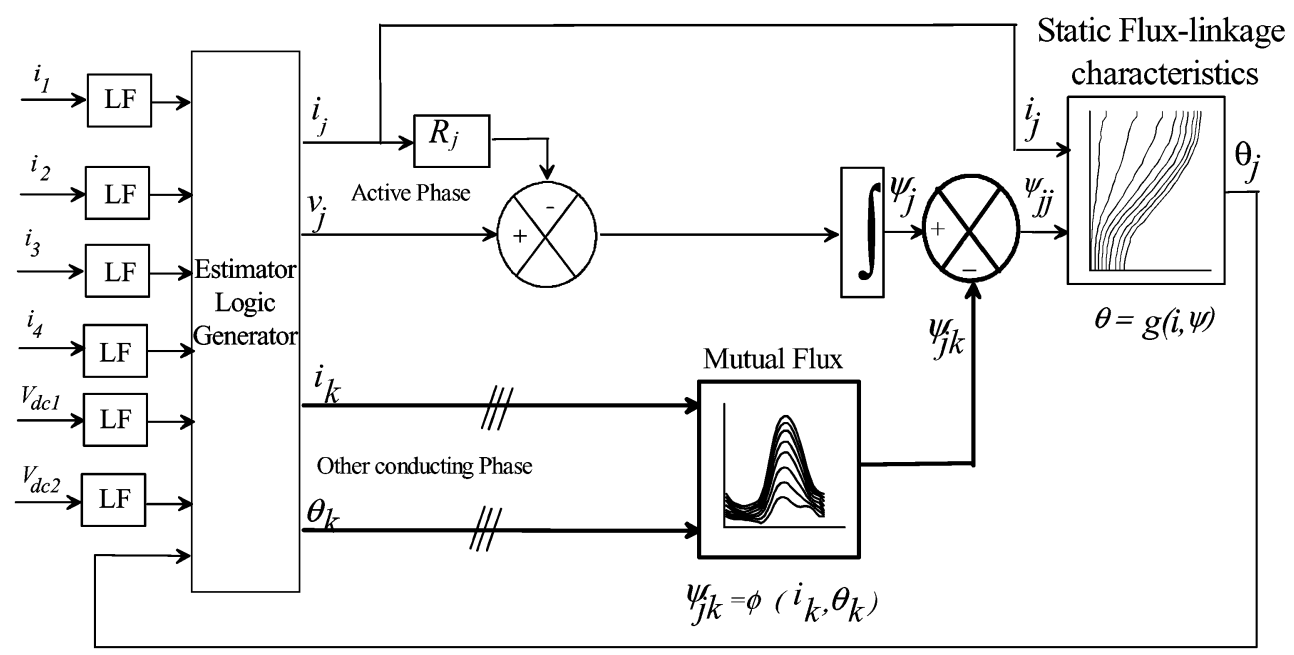

Fig. 14. Position estimation block-diagram considering mutual flux.

(i)

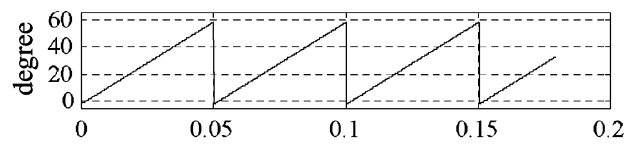

(ii)

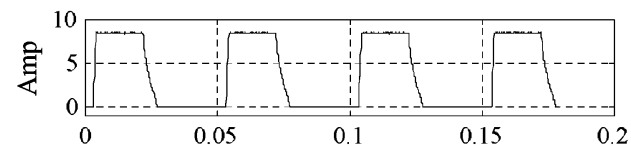

(iii)

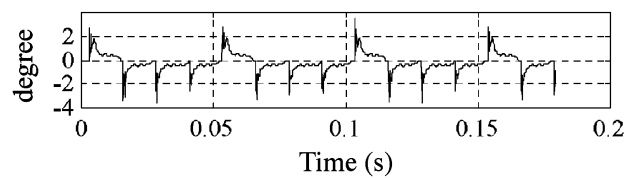

(a) (i)

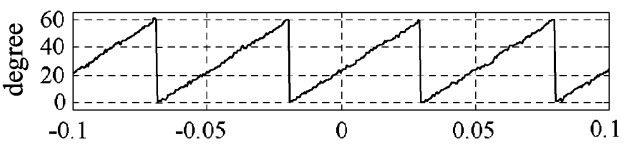

(ii)

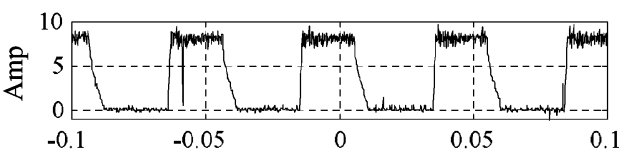

(iii)

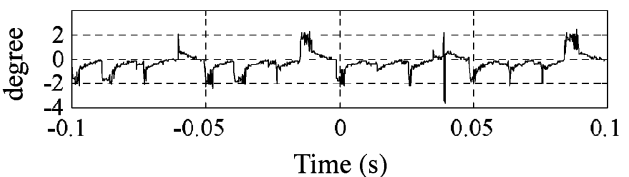

(b)

Fig. 15. (a) Simulation and (b) experimental results of (i) estimated position, (ii) phase 1 current and (iii) error in estimation due to mutual flux only, at 200 rpm. $\left(\mathrm{Vdc}=130 \mathrm{~V}, \mathrm{~T}\right.$-on $=3.75^{\circ}, \mathrm{T}$-off $=26.25^{\circ}$, load $\left.=11.5 \mathrm{Nm}\right)$.

\section{B. Results of Position Estimation}

The effect of position estimation is studied first in simulation. The simulation results of estimated position, phase current, and error due to mutual flux at 200 and $1400 \mathrm{rpm}$ are given in Fig. 15(a) and Fig. 16(a), respectively. It shows that mutual fluxes alone can introduce an error of $\pm 3^{\circ}$. The same is verified in experiment. The experimental results are shown in Fig. 15(b) and Fig. 16(b) for the above operating conditions. It is also observed the net error in position estimation is reduced after correcting for the mutual fluxes. A typical test result (at $1875 \mathrm{rpm}$ ) of estimated position with and without mutual flux, and actual position along with net error (actual-estimated) in estimation are given in Fig. 17(a) and (b).

\section{DISCUSSION}

The effects of mutual flux on phase current, phase flux, and energy conversion contour for the different phases of an $8 / 6$ pole SR motor are demonstrated through simulation results. It is shown that for same T-on, T-off, $\mathrm{I}^{*}$ and same excitation voltage and for unipolar excitation, the current and flux waveforms in different phases are unequal due to mutual flux. In effect, the load sharing among the different phases is not the same. For example, the energy conversion due to $\mathrm{Ph} 4$ is considerably less than that due to Ph1 (see Fig. 11 and Fig. 13). This will cause the under-utilization of $\mathrm{Ph} 4$ compared to $\mathrm{Ph} 1$. Hence, for uniform utilization of the different phases, the T-on and T-off angles for high speeds and current references for low speeds are suggested to be different. These findings may be used for control purposes in order to improve the performance in terms of energy density, torque ripple, and smooth operation of the machine. These findings may be used in the design stage as well for selecting the number of poles and phases depending on the performance requirement of the load.

\section{A. Choice of Even and Odd Number Phase SR Motors Pertinent to Mutual Coupling}

Choice of even or odd number phases for the design of SR motors is important for effective utilization of mutual flux. It has been shown in Section II that a SR motor with even number phase produces asymmetric mutual coupling between the phases. Very recently, Edrington et al. [12] have reported such asymmetry between different phases and suggested bipolar excitation of the phases. These bipolar excitation supports short flux path uniformly for all the phases at twice the cost of the semiconductor devices. The present authors also reported this asymmetry between phases for unipolar excitation in an earlier 
(i)

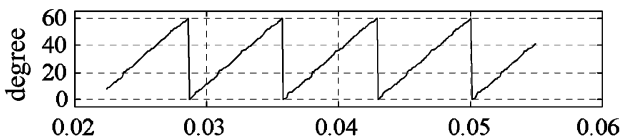

(ii)

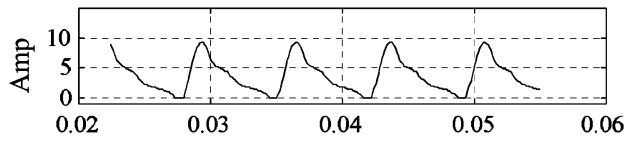

(iii)

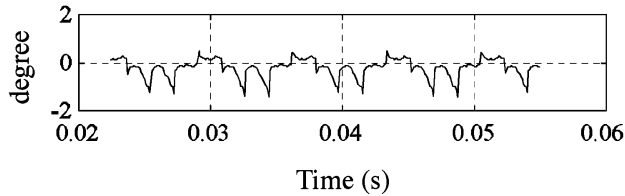

(a) (i)

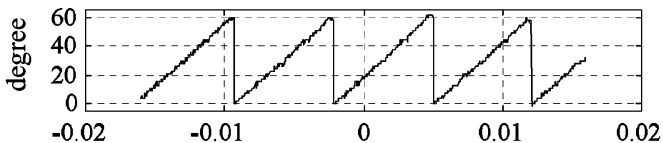

(ii)

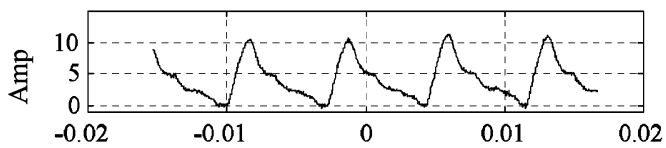

(iii)

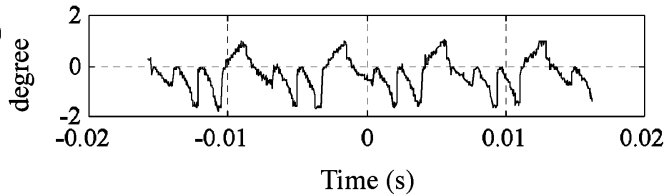

(b)

Fig. 16. (a) Simulation and (b) experimental results of (i) estimated position, (ii) phase 1 current, and (iii) error in estimation due to mutual flux only, at $1400 \mathrm{rpm}$. $\left(\mathrm{Vdc}=130 \mathrm{~V}, \mathrm{~T}\right.$-on $=-5^{\circ}, \mathrm{T}$-off $\left.=22.5^{\circ}, \mathrm{load}=7.5 \mathrm{Nm}\right)$.

(i)

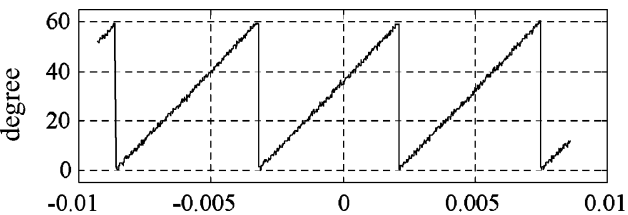

(ii)

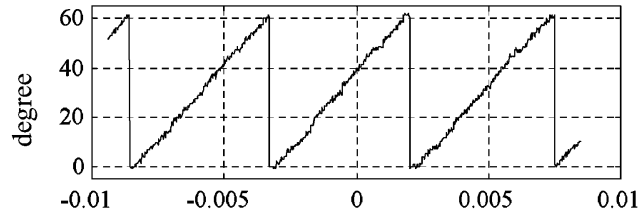

(iii)

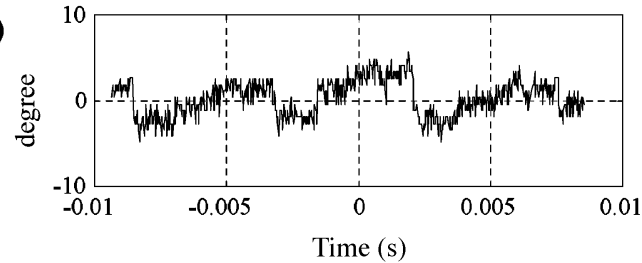

(a) (i)

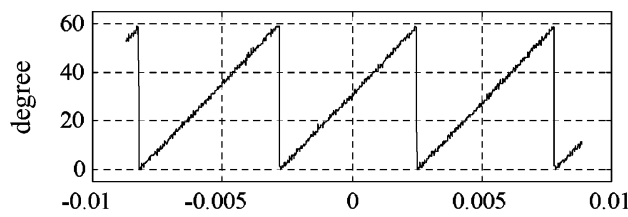

(ii)

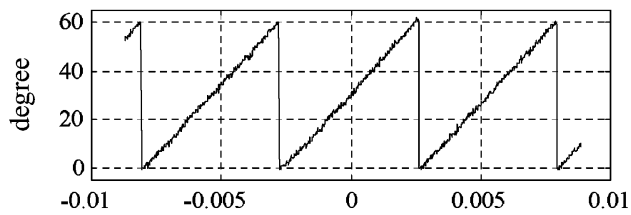

(iii)

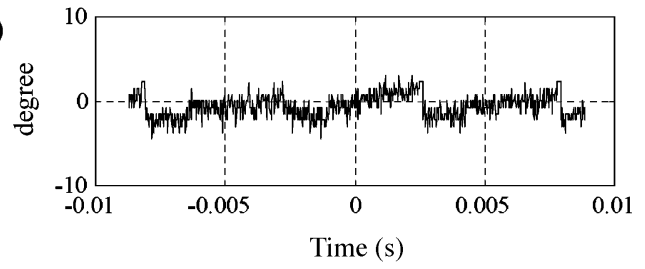

(b)

Fig. 17. Experimental result of (i) actual position, (ii) estimated position, and (iii) net error in estimation at 1875 rpm (a) without considering mutual flux and (b) considering mutual flux.

conference publications [4], [14]. In such case of asymmetry, instead of using an even number of phase machines it will be prudent to use an odd number of phase machines (such as three-phase 6/4 motor, five-phase 10/8 motor, etc). It has been shown earlier in this paper that an odd number of phase machines provides symmetric mutual flux in all the phases and at the same time it supports short flux path. Thus, by using a five-phase 10/8 pole machine symmetrical operation from all the phases can be obtained, short flux path operation can be achieved, and also it will not need costly bipolar excitation of the phases as suggested in [12]. In case of bipolar excitation, a four-phase motor will require total 16 switches, whereas in case of five-phase motor only 10 switches will be sufficient and at the same time flux-path will be even shorter compared to a four-phase motor. Also, a five-phase motor will have reduced torque ripple compared to a four-phase motor [6], [13] for a similar power rating application. Thus, it can be concluded that an odd number of phase machines is a better alternative compared to bipolar converter driven even number phase motor. However, for a low-cost application, still a four-phase motor (or even number of phase motors) will be a better choice since it can be operated by a split-capacitor type power converter where each phase requires only one switch.

\section{B. Saturation Effect on Mutual Coupling}

This analysis assumes that superposition principle holds good in accommodating mutual flux into the machine model, dynamic simulation, and position estimation algorithm. In reality, the SR motor will operate with saturation and mutual flux effect will be somewhat reduced due to such saturation. In the linear operating zone, the magnitude of the actual asymmetry will be the same and in saturation the effect will be somewhat less than what is presented here. Thus, it can be concluded that the actual asymmetry between the phases will be either equal or less than the asymmetry shown in this paper. Therefore, the presented results in this paper can be considered as the maximum boundary for 


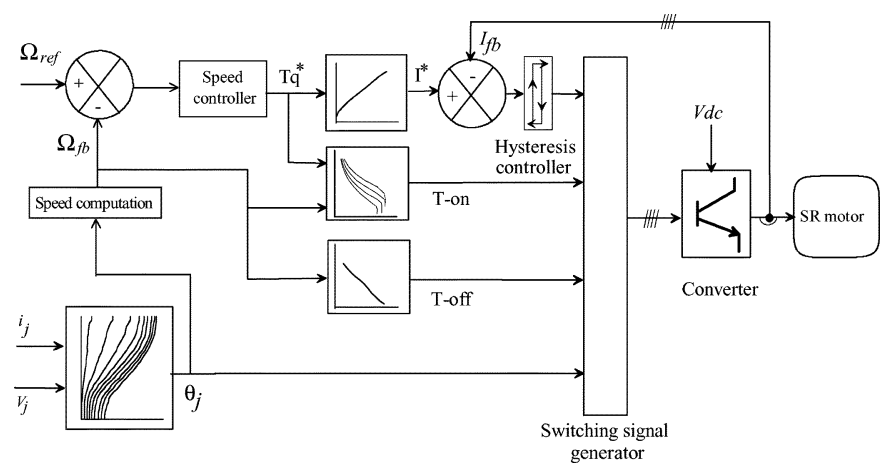

Fig. 18. Block diagram for the proposed SR motor controller.

asymmetry between the phases. The present analysis gives an idea to the designer about the maximum asymmetry between the phases and depending on applications a designer can choose whether it will be cost effective to compensate this asymmetry by introducing design or controller complexity. Again, it can be mentioned here that irrespective of saturation mutual coupling effect for even number phase motors will remain asymmetric and the same will be symmetric for odd number phase motors. Thus, this paper establishes the asymmetry for even number of phase machine, gives the upper boundary of the asymmetry, and suggests to choose an odd number of phase SR motors for high-performance applications.

In order to avoid the saturation effect, the position estimation algorithm in this paper is restricted in the linear operating zone. It may be seen from Figs. 15 and 16 that current is restricted to only in the linear operating zone [either below 7 A near the aligned region or with higher current within the unaligned inductance region (typically within $10^{\circ}$ )]. Thus, the saturation effect is largely avoided in the present position estimation algorithm. Again, the focus here is to show that substantial impact will be there in position estimation due to mutual coupling effect and the same is demonstrated with the given experimental results. The mutual coupling effect on position estimation in saturation can be taken up as future study.

\section{CONTROLler REALIZATION AND EXPERIMENTAL HARDWARE}

Apart from the position estimator, the control of SR motor involves a number of operations such as speed computation, execution of speed and current controller, execution of torque to current conversion, T-on and T-off angle selection (Turn-on and Turn-off angle of each phase), and final switching logic generation, etc. The block diagram of a complete controller is shown in Fig. 18. A PI controller serves as speed controller and the current control is realized through hysteresis controller. The algorithm is tested on a $4 \mathrm{~kW}$, four-phase, $8 / 6$ pole Oulton motor. A split-capacitor link power converter is used for controlling the motor. The schematic of the power converter is shown in Fig. 19.

\section{A. DSP Controller}

The execution of the control scheme (including the estimator) as discussed above is time critical. A digital controller is an ideal

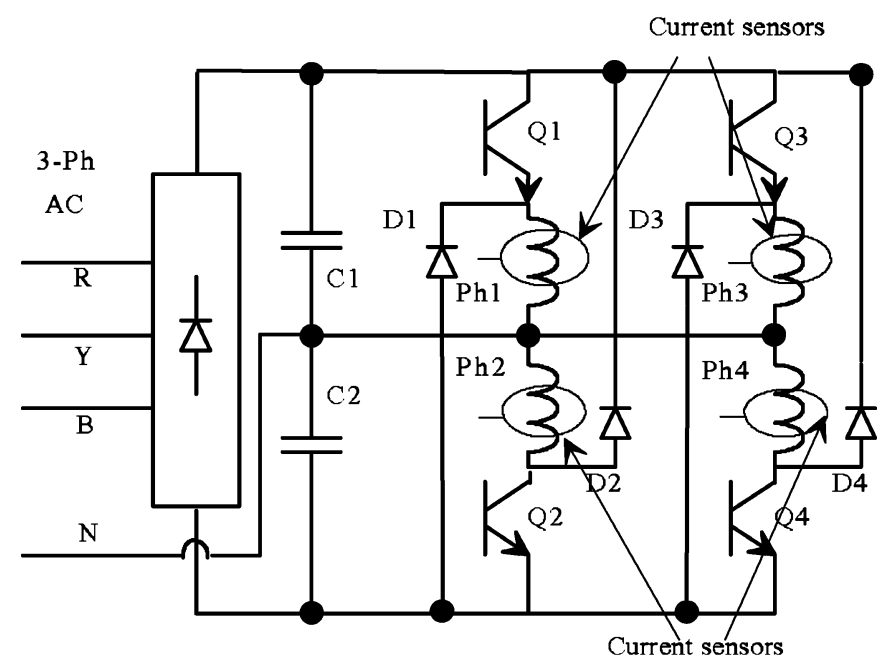

Fig. 19. Power converter for the proposed SR motor drive.

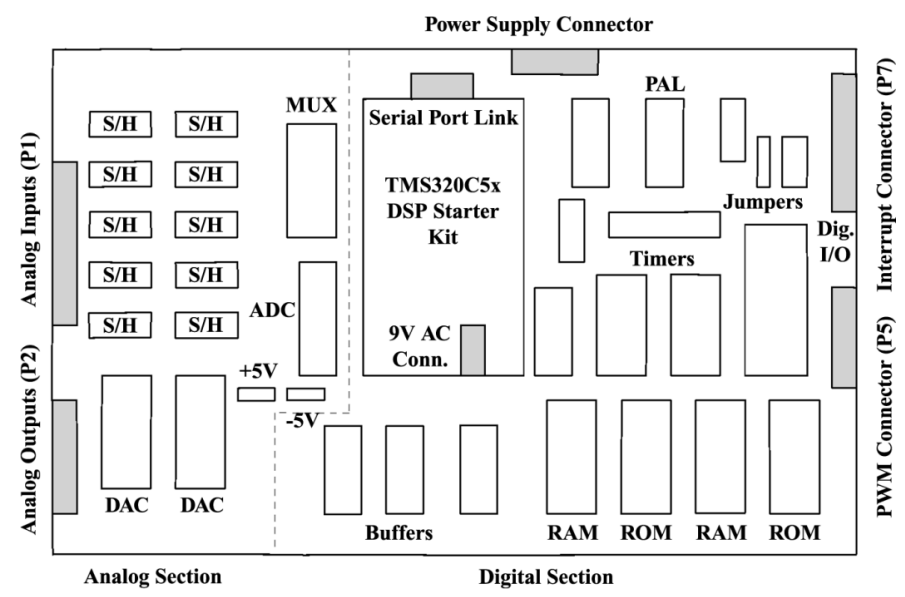

Fig. 20. Schematic of the DSP board used for realizing the controller.

choice for realizing such controllers. In this work, a Texas Instruments 16-bit $40 \mathrm{MHz}$ fixed point DSP (TMS320c50) is used for controlling the SR motor. A general purpose DSP board is fabricated for realization of this controller. The schematic of the board is given in Fig. 20. For this particular application, one digital output port and six ADC channels (for four phase currents and two dc link voltages) are used. With the help of DSP, the sampling and execution time achieved for the whole control process is $100 \mu \mathrm{s}$.

\section{B. Experimental Hardware}

The complete experimental hardware used for testing the proposed control scheme is shown in Fig. 21. The main power converter (left) and the front end rectifier (middle) are mounted on the workbench as shown in the picture. A desktop computer is used to download the DSP software through an XDS510 emulator. A fixed point TI DSP is used for executing the control algorithm. A four-phase Oulton SR motor (right) along with a $\mathrm{dc}$ machine (left) is coupled with a torque transducer and can be seen in the picture as mounted on the base. The dc machine is used here to emulate the fan type of load. The dc machine output is connected to a bank of rheostats for varying the load. A four-channel HP scope is used for monitoring and recording 


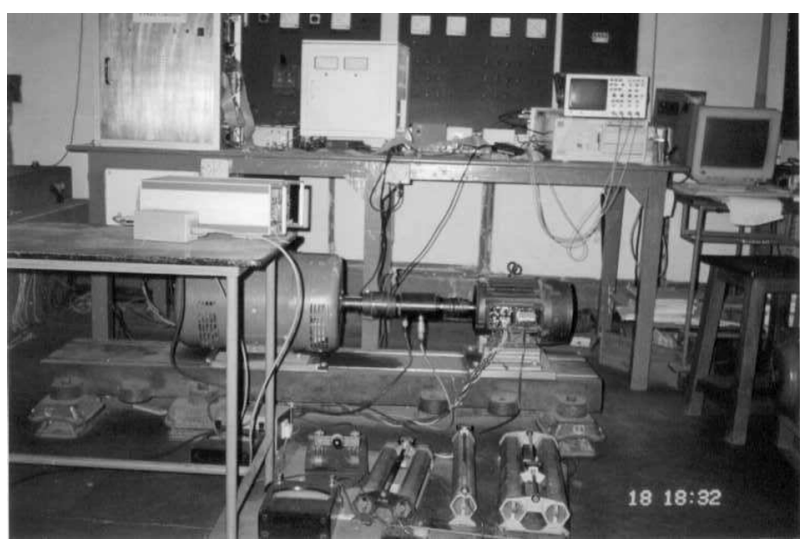

Fig. 21. Experimental hardware setup.

TABLE I

SR MOTOR PARAMETERS

\begin{tabular}{|l|l||l|l|}
\hline Stator Poles & 8 & Rotor Poles & 6 \\
\hline Rated Power & $4 \mathrm{~kW}$ & Rated Speed & $1500 \mathrm{rpm}$ \\
\hline Rated Voltage & $280 \mathrm{~V} /$ phase & Rated Phase Current & $18 \mathrm{~A}$ \\
\hline Phase Resistance & $0.7 \Omega$ & Min. Inductance & $10 \mathrm{mH}$ \\
\hline Max. Inductance & $110 \mathrm{mH}$ & SR motor Inertia & $0.008 \mathrm{Nm}-\mathrm{s}^{2}$ \\
\hline System Inertia & $0.08 \mathrm{Nm}-\mathrm{s}^{2}$ & System friction coeff. & $0.0065 \mathrm{Nm}-\mathrm{s}$ \\
\hline
\end{tabular}

the waveforms. The parameters of the $8 / 6$ pole SR motor used for testing and analysis are presented in Table I.

\section{CONCLUSION}

In this paper, the effect of mutual flux in SR motor is analyzed and illustrated through simulation and experiment. It is shown that the distribution of mutual flux for any SR motor with an even number of phases and with unipolar excitation is inherently asymmetric. The asymmetry between phases can be compensated at the expense of complex motor and controller. To the best knowledge of the authors, the asymmetry due to mutual coupling and its remedy had not been explored and analyzed explicitly until some mention in earlier conference publications [4], [14] by the authors themselves. Very recently, Edrington et al. [12] suggested bipolar excitation as a remedy for such asymmetry. However, these bipolar excitations are very expensive and not practical for most of the applications. Also, in their analysis they have considered only a particular winding configuration for even number of phase motor. They have not included any odd number of phase motors in their analysis. In this analysis, different possible winding configurations for both even and odd number phase SR motors are shown and their relative merits are explained and finally the best configuration is identified in each category. Most importantly, it has been shown in this paper that an odd number phase SR motor with proper winding configuration [see Fig. 2(a)] is capable of producing symmetric mutual coupling and thus does not need any complex controller. In such odd number phase machine, mutual coupling effect adds to the self flux and also provides short flux path even under unipolar excitation. Thus, potentially the torque capability of the machine will be increased in case of odd number phase motor. However, the actual percentage increase of torque may vary due to motor structure, number of poles, and number of phases and it needs to be verified through an actual test and may be considered in future work. Therefore, for high-performance application a SR motor should be designed with an odd number of phases. On the other hand, for low-cost applications a SR motor with even number of phase motor is still attractive since it can be used with a split-capacitor type converter (see Fig. 19) where only one switch is required for each phase. However, performance of such motor will be slightly degraded due to asymmetry of the phases due to mutual coupling.

In addition, a practical mutual flux measurement method between the adjacent phases are proposed and a detailed experimentally measured mutual flux of SR motor for an $8 / 6$ pole SR motor has been illustrated. These experimentally measured mutual flux can be utilized for modeling the motor. Finally, a more accurate position estimation algorithm using the correction for mutual fluxes is demonstrated. It is shown through experiment that mutual flux, if not corrected, may introduce an error as much as $\pm 3^{\circ}$ in the estimated rotor position. The drawback of the present analysis is that the estimation algorithm is only confined to the linear operating zone. The impact of mutual coupling for position estimation in the saturation zone should be explored in future work.

In totality, this paper establishes the asymmetry of mutual flux for even number of phase machine, gives the upper boundary of such asymmetry, and suggests to choose an odd number of phase SR motors for high-performance applications. Also, this paper demonstrates that position estimation accuracy in SR motor can be improved considering the mutual coupling effect.

\section{ACKNOWLEDGMENT}

This work was supported by the Indian Institute of Science.

\section{REFERENCES}

[1] J. M. Stephenson and J. Corda, "Computation of torque and current in doubly-salient reluctance motors from nonlinear magnetisation data," Proc. IEE, vol. 126, no. 5, pp. 393-396, 1979.

[2] N. N. Fulton and J. M. Stephenson, "A review of switched reluctance machine design," in Int. Conf. Electrical Machines, 1988.

[3] H. H. Moghbelli, G. E. Adams, and R. G. Hoft, "Prediction of the instantaneous and Steady state torque of the switched reluctance motor using finite element method (FEM)," in Proc. IEEE IAS Annu. Meeting, 1988, pp. 59-70.

[4] D. Panda and V. Ramanarayanan, "Effect of mutual inductance on steady-state performance and position estimation of switched reluctance motor drive," in IEEE Industry Application Soc. Annu. Meeting, Phoenix, AZ, 1999, pp. 2227-2234.

[5] V. Ramanarayanan, L. Venkatesha, and D. Panda, "Flux-linkage characteristics of switched reluctance motor," in IEEE Int. Conf. Power Electronics, Drives and Energy Systems for Industrial Growth (PEDES'96), Delhi, Jan. 1996, pp. 281-285.

[6] T. J. E. Miller, Switched Reluctance Motors and Their Control. Oxford, U.K.: Clarendon, 1993.

[7] T. J. E. Miller and M. McGilp, "Nonlinear theory of the switched reluctance motor for rapid computer-aided design," IEE Proc., vol. 137, no. 6, pt. B, pp. 337-346, Nov. 1990.

[8] J. C. Moreira and T. A. Lipo, "Simulation of a four phase switched reluctance motor including the effects of mutual coupling," Elect. Mach. Power Syst., vol. 16, pp. 281-289, 1989.

[9] R. M. Davis and I. H. Al-Bahadly, "Experimental evaluation of mutual inductance in a switched reluctance motor," in 4th IEEE Int. Conf. Power Electronics and Variable Speed Drives, London, U.K., 1991, pp. 243-248.

[10] J. P. Lyons, S. R. Macminn, and M. A. Preston, "Flux/current methods for SRM rotor position information," in IEEE IAS Conf., 1991, pp. 482-487.

[11] D. Panda and V. Ramanarayanan, "Accurate position estimation in switched reluctance motor with smooth starting," in IEEE Industrial Electronics Conf., ICIT, Jan. 2000, pp. 388-393. 
[12] C. S. Edrington, D. C. Kauvagunta, J. Joddar, and B. Fahimi, "Investigation of electromagnetic force components in SR machines: Design and control issues," in IEEE IAS Annu. Meeting, 2003, vol. 1, pp. 219-226.

[13] R. Krishnan, Switched Reluctance Motor, 1st ed. Boca Raton, FL: CRC, 2001.

[14] D. Panda and V. Ramanarayanan, "An accurate position estimation method for switched reluctance motor drive," in IEEE Int. Conf. Power Electronics Drives and Energy Systems (PEDES), Perth, Australia, Dec. 1998 , pp. 523-528.

[15] H.-Y. Bae and R. Krishnan, "A novel approach to control of switched reluctance motors considering mutual inductance," in IEEE Industrial Electronics Soc. Conf., 2000 (IECON 2000), vol. 1, pp. 369-374.

[16] M. A. Preston and J. P. Lyons, "A switched reluctance motor model with mutual coupling and multi-phase excitation," IEEE Trans. Magn., vol. 27, no. 6, pp. 5243-5245, Nov. 1991.

[17] P. Pillay, Y. Liu, W. Cai, and T. Sebastin, "Multiphase operation of switched reluctance motor drives," in Proc. IEEE IAS Annu. Meeting, 1997, vol. 1, pp. 310-317.

[18] J. M. Koternak and D. A. Torey, "Magnetic circuit model for the mutually coupled switched reluctance machine," IEEE Trans. Magn., vol. 36, no. 2, pp. 500-507, Mar. 2000.

[19] P. P. de Paula, W. M. da Silva, J. R. Cardoso, and S. I. Nabeta, "Assessment of the influence of the mutual inductances on switched reluctance machine performance," in Proc. IEEE IEMDC 2003, vol. , pp. $1732-1738$.

[20] M. Farshad, J. Faiz, and C. Lucas, "Development of analytical models of switched reluctance motor in two-phase excitation mode: Extended Miller model,' IEEE Trans. Magn., vol. 41, no. 6, pp. 2145-2155, Jun. 2005.

Manuscript received September 16, 2005; revised April 22, 2007. Corresponding author: D. Panda (e-mail: dpanda@ieee.org).
Debiprasad Panda (M'99) was born in Doldere, India, in 1968. He received the B.E. and M.E. degrees from Calcutta University in 1991 and 1994, respectively, and the Ph.D. degree from Indian Institute of Science, Bangalore, India in 2000.

During 2000-2003, he was a Post-Doctoral Fellow at WEMPEC, University of Wisconsin, Madison. From 2003 to 2006, he held a Senior Principal Engineer position at Rockwell Automation Advanced Technology lab, Richmond Heights, OH. He is now with Trans-Coil Inc., Milwaukee, WI, working as the lead Power Electronics Engineer for the new Electronic Product Division. His field of interest includes electronic power conversion, variable speed drive, wind energy, power quality, DSP-based control, and specialty motors.

V. Ramanarayanan received the B.E. degree from the University of Madras, Madras, India, in 1970, the M.E. degree from Indian Institute of Science, Bangalore, India, in 1975 and the Ph.D. degree from the California Institute of Technology, Pasadena, in 1986.

He is a Professor in the Department of Electrical Engineering, Indian Institute of Science, Bangalore. He held positions in industry as a Senior Design Engineer with M/S Larsen and Toubro Ltd. (1970-79) and as Chief of Research and Development with NGEF Ltd (1979-82). His areas of interest are power electronics, industrial drives, switched mode power conversion, and power quality issues. He is a consultant of several industries in related areas. He also currently holds the position of the academic Co-ordinator of National Mission on Power Electronics Technology (NaMPET) of India. 